The Korean Communications

in Statistics Vol. 10 No. 2, 2003

pp. $423-432$

\title{
Spatial Data Analysis using the Kriging Method
}

\author{
Jihui Jang1) Taekyong Hong2) Pyong Namkung3)
}

\begin{abstract}
The data observed at different positions are called the estimate of interested variable at new observation point on the Kriging utilize the space estimate technique, in which case there is correlation spatially. In this paper we provide the estimate for Variogram and Kriging methods as a field of kriging theory and dealt with actually measured data. And at the same time we forecast the amount of ozone that was not measured at this point by Kriging method and compared Ordinary Kriging method with Inverse Distance Kriging method.
\end{abstract}

Keywords : Kriging, Variogram, Spatial estimation, Ozone levels

\section{1. 서론}

크리깅에 의한 예측방법은 원래 지질통계학 분야에서 널리 이용되었던 기법으로 현재는 많은 분야에서 활용되고 있다. 특히 관측점이 불규칙한 경우에 등고선이나 곡면의 보간 등에 유용하다. 크리깅은 확률과정모형을 바탕으로 한 공간 자료에 대한 통계적 모형은 다음 식과 같으며 공간에 대해서 연속이라는 가정 하에 예측하게 된다.

$$
Z(s)=\{s \mid s \in D\}, \quad D \subset R^{d}
$$

여기서 $Z(s)$ : 거리 $s$ 에 대한 함수,

$s$ : 각 표본들 간의 거리,

$D$ : 표본이 위치하고 있는 공간, $R^{d}: d$ 차원의 공간

크리깅 방법에는 평균을 안다는 가정 하에 사용하는 가장 간단한 방법인 단순 크리깅(Simple Kriging)과 평균은 미지이나 일정하다는 가정 하에 널리 이용되는 방법인 보통 크리깅(Ordinary Kriging), 평균의 경향성을 고려한 방법인 보편 크리깅(Universal Kriging) 그리고 거리에 영향을 받는 비확률적인 방법인 거리역수 크리깅(Inverse Distance Kriging)등 여러 가지 방법이 있다. 이

1) Researcher, ADN, 91-3, Nonhyeon-dong, Gangnam-gu, Seoul, 135-010, Korea.

2) Lecturer, Department of Computer Information Processing, Yongin University, 470, Samga-dong, Yongin-si, Gyeonggi-do, 449-714, Korea.

3) Professor, Department of Statistics, Sungkyunkwan University, Seoul, 110-745, Korea.

E-mail : namkung@skku.ac.kr 
러한 크리깅 방법은 자료의 경향과 자료의 특성을 차의 분산(Variogram)으로 나타내며, 적절한 차 의 분산모형이 설정되어 있으면 예측을 효율적으로 할 수 있다.

본 논문에서는 단순 크리깅은 실제 데이터에 적용시키기에는 현실성이 결여되고, 보편 크리깅의 경우는 자료의 경향성을 알 수가 없기 때문에 두 크리깅 방법을 제외한 보통 크리깅 방법과 거리 역수 크리깅 방법을 적용하여 서울시의 오존 오염도를 예측하였다.

\section{2. 차의 분산}

\section{1 경험적 차의 분산}

경험적 차의 분산은 각 표본간의 거리 및 이들의 오존도의 상관성을 나타낸 것으로 경험적 차 의 분산을 작성하기 위해서는 각 표본들을 나열한 후 추정이 필요한 지점에서 거리가 가까운 표 본 위치 지점부터 가장 먼 표본 위치 지점까지 거리에 포함된 표본들 간의 상관관계를 나타내야 한다.

이 경험적 차의 분산은 마테론(1962)이 제시하였으며, 다음 식으로 구한다.

$$
2 \hat{r}(h)=\frac{1}{|N(h)|} \sum_{h(h)}\left(Z\left(s_{i}\right)-Z\left(s_{j}\right)\right)^{2}, \quad h \in R^{d}
$$

\section{2 이론적 차의 분산}

$s_{0}=(x, y)$ 에 대해 $Z\left(s_{0}\right)$ 을 예측하는데 필요한 정보를 얻기 위해 경험적 차의 분산에 이론적인 모형을 적합시킨다. 이론적 모형의 함수식은 여러 가지가 있지만 가우스 모형만을 고려한다.

$$
\gamma(h: \theta)= \begin{cases}0, & h=0 \\ C(0)\left[1-\exp \left(-\frac{\|h\|^{2}}{a_{s}^{2}}\right)\right], & h \neq 0\end{cases}
$$

여기서 $\theta=\left(C(0), a_{s}\right)^{\prime}, \quad C(0) \geq 0, a_{s} \geq 0$

\section{3. 크리깅}

\section{1 보통 크리깅}

보통 크리깅은 널리 이용되는 방법으로 모형의 평균 $(\mu)$ 은 사전에 알 수 없고 일정하다는 전제 하에 예측하는 방법이다. 모형가정과 예측값에 대한 가정은 다음과 같다. 
$Z(s)=\mu+\delta(s), \quad s \in D, \quad \mu \in R, \quad \mu=$ unknown $\widehat{Z}\left(s_{0}\right)=\sum_{i=1}^{n} \lambda_{i} Z\left(s_{i}\right), \quad \sum_{i=1}^{n} \lambda_{i}=1$

여기서, $\mu$ 는 미지이고 $\sum_{i=1}^{n} \lambda_{i}=1$ 이라는 조건은 불편성을 만족하는 조건이다.

\section{2 거리역수 크리깅}

거리역수 크리깅은 주변표본들의 $Z\left(s_{i}\right)$ 이 미 측정지점의 $Z\left(s_{0}\right)$ 사이가 거리의 영향을 받는 방법 을 말한다. 즉 거리에 역을 취한 값들을 가중값으로 환산하는 방법이다. 예측값 가정은 다음과 같 다

$$
\mathcal{Z}\left(s_{0}\right)=\sum_{i=1}^{n} w_{i} Z\left(s_{i}\right), \quad\left(\sum w_{i}=1, w_{i}=f\left(h_{i}\right)\right)
$$

여기서 $Z\left(s_{0}\right)$ 는 미 측정지점에서의 예측값이고, $Z\left(s_{i}\right)$ 는 표본들의 관측값이며 $w_{i}$ 는 표본들의 가 중값이다.

\section{4. 사례연구}

서울의 오존 분포도를 그려보기 위한 준비 단계로 차의 분산을 추정하고 이를 크리깅 방법을 적용하여 미 측정지역의 오존도를 예측해보고, 입의의 한 측정소가 측정기의 고장으로 오존도를 측정할 수 없다는 가정하에 크리깅 방법들의 예측을 비교한다.

\section{1 미 측정지역의 오존도 예측}

미 측정지역 오존도의 예측을 위해 <표 1>에 제시된 서울의 27 개 지역의 2000 년 평균 오존자료를 이용하였으며 각 측정소별 위치는 기준점(시청앞)과의 가로-세로 거리 $(\mathrm{km})$ 를 $\mathrm{TM}$ (Transverse Mercator; 평면직각좌표계)좌표를 이용하여 나타낸 것이다.

\subsection{1 차의 분산 추정}

원자료를 이용한 적합에서 측정된 지점으로부터 얻은 351 개의 표본 반차의 분산을 이용하여 이론적 인 반차의 분산을 추정하여 적합을 하면, 모형적합의 정확도면에서는 신뢰성이 있는 방법이나 시 간이 너무 많이 걸린다는 단점을 지니고 있다. 따라서 본 논문에서는 시간문제를 해결하기 위해 마테론(1962)이 제안한 lag방법을 적용하였다.

<표 2>와 같이 구간 수가 달라짐에 따라서 추정된 차의 분산의 형태에 차이가 있음을 확인 할 수 있다. 따라서 구간을 나누는 방법을 사용할 때 원 자료를 잘 설명해주는 구간 수의 선택 기준에 대한 
보다 집중적인 연구가 필요하다. 분석 시 원 자료와 비슷한 차의 분산 모형을 갖는 $\mathrm{lag}=7$ 을 선택하여 결과를 살펴보았다.

<표 3>을 보면 351 개의 거리 쌍들의 점이 거리구간별로 해당 거리에 분포되어 있음을 알 수 있다. 올바른 예측을 하기 위해서는 많은 거리 쌍들의 점을 가지고 차의 분산을 계산해야 한다. 여기서 구간 폭이 작다는 것은 가능한 많은 거리구간을 갖는다는 것과 동일한 의미이다. 그러나 차의 분산을 계산하기 위해선 각 구간 내에 적어도 30 개의 쌍들의 점을 사용해야 한다. 만약 구간 폭이 매우 작다면 하나 또는 그 이상의 구간에서는 매우 작은 쌍들의 점을 갖게 될 것이다. 반면 에 구간 폭이 매우 크다면 거리구간 내에 포함된 쌍들의 점의 수는 예측을 위해 뗠요이상이 될 것이 다.

<표 1> 서울의 측정소 위치와 2000년 오존오염도 자료

\begin{tabular}{|c|c|c|c|c|c|c|c|}
\hline \multirow{2}{*}{ 측정소명 } & \multicolumn{2}{|c|}{$\begin{array}{l}\text { 기준점(시청 앞) } \\
\text { 과의 거리 }(\mathrm{km})\end{array}$} & \multirow{2}{*}{$\begin{array}{c}2000 \text { 년 } \\
\text { 오존오염도 } \\
\text { (ppm) }\end{array}$} & \multirow{2}{*}{ 측정소명 } & \multicolumn{2}{|c|}{$\begin{array}{l}\text { 기준점(시청 앞) } \\
\text { 과의 거리 }(\mathrm{km})\end{array}$} & \multirow{2}{*}{$\begin{array}{c}\text { 2000년 } \\
\text { 오존오염도 } \\
\text { (ppm) }\end{array}$} \\
\hline & 가로 & 세로 & & & 가로 & 세로 & \\
\hline 시청앞 & 0 & 0 & 0.014 & 길음동 & 4.470 & 4.477 & 0.020 \\
\hline 이화동 & 1.982 & 1.144 & 0.018 & 한남동 & 2.622 & -2.886 & 0.018 \\
\hline 면목동 & 8.792 & 2.509 & 0.018 & 구의동 & 10.282 & -2.326 & 0.017 \\
\hline 신설동 & 4.210 & 0.656 & 0.015 & 성수동 & 7.002 & -1.796 & 0.013 \\
\hline 불광동 & -3.881 & 4.960 & 0.022 & 방학동 & 5.582 & 10.234 & 0.022 \\
\hline 마포 & -2.540 & -2.253 & 0.018 & 남가좌동 & -5.548 & 0.794 & 0.013 \\
\hline 문래동 & -7.531 & -5.671 & 0.018 & 구로동 & -7.148 & -9.406 & 0.016 \\
\hline 사당동 & -0.198 & -8.556 & 0.010 & 반포동 & 1.662 & -6.816 & 0.017 \\
\hline 관악산 & -1.914 & -12.219 & 0.027 & 화곡동 & -13.308 & -2.036 & 0.015 \\
\hline 대치동 & 7.062 & -8.066 & 0.017 & 방이동 & 13.122 & -4.906 & 0.017 \\
\hline 잠실동 & 9.470 & -6.665 & 0.016 & 신정동 & -10.468 & -4.606 & 0.015 \\
\hline 시흥동 & -5.898 & -12.606 & 0.010 & 상계동 & 8.312 & 10.294 & 0.024 \\
\hline 천호동 & 12.982 & -2.806 & 0.016 & 궁동 & -12.918 & -7.256 & 0.017 \\
\hline 번동 & 4.672 & 7.604 & 0.014 & & & & \\
\hline
\end{tabular}


<표 2> lag를 이용한 오존자료의 차의 분산 모형적합

\begin{tabular}{c||c|c}
\hline & $C(0)$ & $a_{s}$ \\
\hline \hline lag=6 & 0.0000165 & 2.0 \\
lag=7 & 0.0000138 & 3.5 \\
lag=8 & 0.0000195 & 3.5 \\
\hline
\end{tabular}

<표 3> 각 쌍들의 거리 구간과 빈도

\begin{tabular}{|c|c|c|c|c|c|c|}
\hline 관촉값 & 변수이름 & LAG & 하한 & 상한 & 빈도 & 백분율 \\
\hline 1 & \multirow{8}{*}{ ozone } & 0 & 0 & 2.4979 & 3 & 0.00855 \\
\hline 2 & & 1. & 2.4979 & 7.4937 & 81 & 0.23077 \\
\hline 3 & & 2 & 7.4937 & 12.4896 & 102 & 0.2906 \\
\hline 4 & & 3 & 12.4896 & 17.4854 & 90 & 0.25641 \\
\hline 5 & & 4 & 17.4854 & 22.4812 & 50 & 0.14245 \\
\hline 6 & & 5 & 22.4812 & 27.477 & 24 & 0.06838 \\
\hline 7 & & 6 & 27.477 & 32.4729 & 1 & 0.00285 \\
\hline 8 & & 7 & 32.4729 & 37.4687 & 0 & 0 \\
\hline
\end{tabular}

<표 3>에서 $\operatorname{lag} 0$ 은 전형적으로 제한된 구간으로 나머지 구간들의 너비 $(4.9958 \mathrm{~km})$ 에 반 $(2.4979 \mathrm{~km})$ 이기 때문에 이 구간에 대해선 차의 분산을 계산하기 위한 약속은 무시된다. 이유는 구간 폭에 따 라 lag0에 포함된 쌍들의 수가 30개 보다 작을 수도 많을 수도 있기 때문이다. 여기서는 $\operatorname{lag} 0$ 에 포함되는 쌍들의 점이 3 개이나 lag1에서 차의 분산을 구하기 위한 충분한 수를 갖고 있으므로 경 험적 차의 분산을 구할 수 있다.

그러나 구간을 나누는 방법에서의 문제점은 독립인 것처럼 보이는 멀리 떨어져있는 점들의 쌍 까지도 포함한다는 것이다. 이를 이용해서 경험적 차의 분산의 모형을 그릴 순 없을 것이다. 그러 므로 상관관계 정도를 예측한다면 지리학적으로 비슷한 장소를 우선으로 열거할 수 있을 것이다. 따라서 가장 많은 쌍들의 점을 갖는 구간은 둘 이상의 구간을 초과하여 상관관계 정도를 예측하 는 것은 의미가 없으므로 그 다음의 하나의 구간만을 고려해야 할 것이다. 이를 통해 빈도가 가장 높은 $\operatorname{lag} 2$ 에서 한 단계 추가한 구간, 즉 분석에 필요한 구간 수가 3 이므로 $\operatorname{lag} 3$ 까지의 차의 분산 을 보면 <표 4 >와 같고, <표 4 >에서의 경험적 차의 분산을 이론적 모형(가우스 모형)에 적용시 켜 보면 <그림 1 >과 같다.

$\mathrm{lag}=7$ 을 선택한 결과가 $C(0)=0.0000138, a_{s}=3.5$ 이므로 적합된 모형식은 다음 같으며 이 모형 식을 이용 크리깅 예측값을 구할 수 있다.

$$
r(h)=0.0000138\left[1-\exp \left(-\frac{\|h\|^{2}}{3.5^{2}}\right)\right]
$$

<표 4> lag3까지의 차의 분산

\begin{tabular}{c||c|c|c|c}
\hline 관측값 & $\begin{array}{c}\text { 각 } \mathrm{lag} \\
\text { 단위 값 }\end{array}$ & $\begin{array}{c}\text { 각 } \mathrm{lag} \text { 에 포함된 } \\
\text { 쌍들의 수 }\end{array}$ & $\begin{array}{c}\text { 각 } \mathrm{lag} \text { 의 } \\
\text { 평균거리 }\end{array}$ & 차의 분산 \\
\hline \hline 1 & -1 & 27 &. &. \\
\hline 2 & 0 & 3 & 2.2246 & 0.0000043 \\
\hline 3 & 1 & 81 & 5.3693 & 0.0000126 \\
\hline 4 & 2 & 102 & 10.1315 & 0.0000118 \\
\hline 5 & 3 & 90 & 14.7701 & 0.0000175 \\
\hline
\end{tabular}




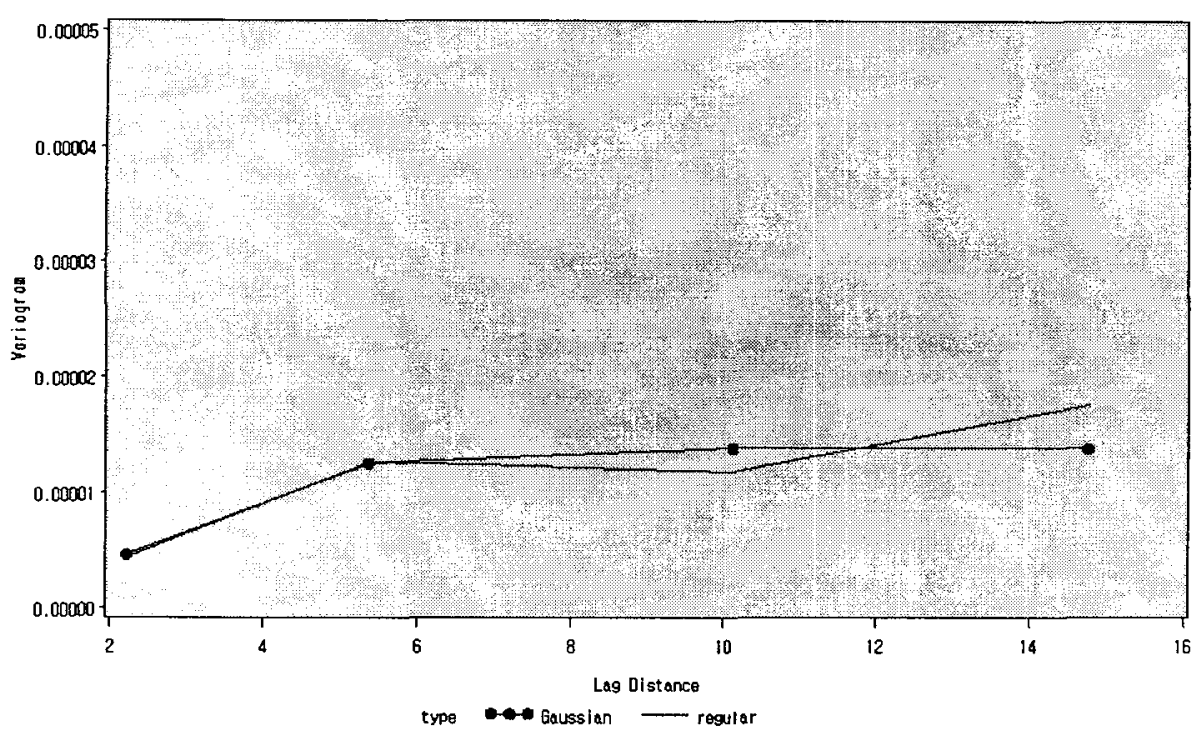

<그립 1>이론적 모형 중 가우스 모형에 적합

\subsection{2 크리깅}

보통 크리깅 방법에서 새로운 위치 $s_{0}$ 즉 고양시, 하남시, 사당- 관악산 주변지역에 대한 예측값 $Z\left(s_{0}\right)$ 는 $\sum_{i=1}^{27} \lambda_{i} Z\left(s_{i}\right)$ 와 같이 각 지역별 크리깅 계수 $\lambda_{i}: i=1,2, \cdots, n$ 와 <표 $1>$ 에서 측정된 27 개의 오존자료를 각각 곱하여 선형 결합함으로서 구할 수 있다.

<표 5>는 세 지역의 크리깅 예측값과 분산, $95 \%$ 예측구간을 정리한 것이며 <그림 2 >는 세 지 역을 포함한 오존 분포도를 등고선으로 표현한 것이며, <그림 3>은 3차원 공간상에 나타낸 반응 표면그림이다.

<표 5> 세 지역의 크리깅 예측값과 분산, $95 \%$ 예측구간

\begin{tabular}{|c|c|c|c|c|}
\hline \multirow[b]{2}{*}{ 지역명 } & \multirow{2}{*}{$\begin{array}{l}\text { 예측값 } \\
Z\left(s_{0}\right)\end{array}$} & \multirow{2}{*}{$\begin{array}{c}\text { 분산 } \\
\sigma_{k}^{2}\left(s_{0}\right)\end{array}$} & \multicolumn{2}{|c|}{$95 \%$ 예측구간 } \\
\hline & & & $\begin{array}{c}\text { 하한 } \\
Z\left(s_{0}\right)-1.96 \sigma_{k}\left(s_{0}\right)\end{array}$ & $\begin{array}{c}\text { 상한 } \\
Z Z Z\left(s_{0}\right)+1.96 \sigma_{k}\left(s_{0}\right)\end{array}$ \\
\hline 1 지역 & 0.0179 & $1.45 \mathrm{E}-05$ & 0.0105 & 0.0254 \\
\hline 2 지역 & 0.0172 & $1.46 \mathrm{E}-05$ & 0.0097 & 0.0247 \\
\hline 3 지역 & 0.0179 & $1.23 \mathrm{E}-05$ & 0.0110 & 0.0247 \\
\hline
\end{tabular}




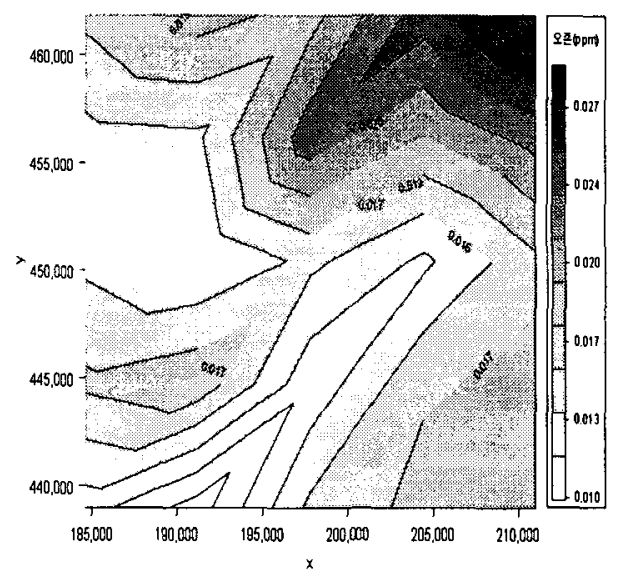

<그림 2> 등고선으로 표현한 오존분포도

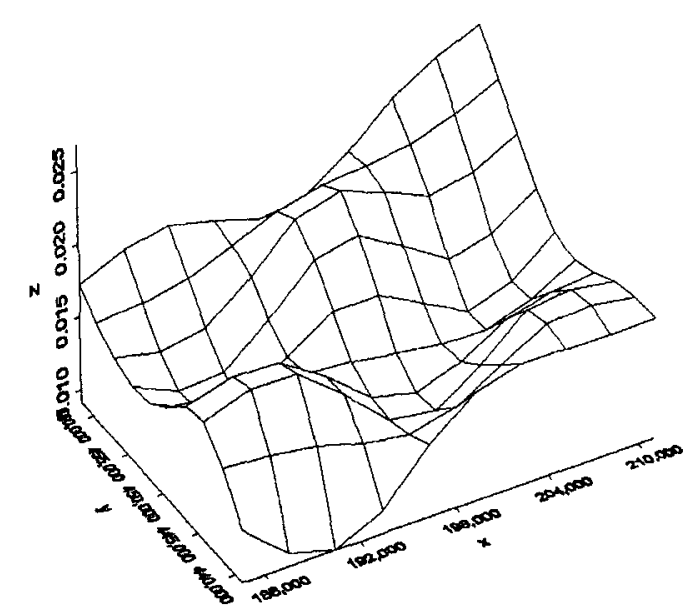

<그림 3> 반응표면으로 표현한 오존 분포도

\section{2 보통 크리깅 방법과 거리역수 크리깅 방법 비교}

오존의 관측지점 중 구의동 지점의 측정장비 고정으로 관측이 안되었다는 가정에서 보통 크리 깅 방법과 거리역수 크리깅 방법 중 어떤 크리깅 방법이 구의동 오존도를 좀 더 잘 예측하는지 알아보도록 하는데 중점을 두었다.

사례연구를 위해 <표 6 >에서와 같이 서울의 27 개 지역의 2000 년 월별 오존자료를 이용하였으 며 각 측정소별 위치자료는 <표 1>을 이용하였다. 단, 성수동과 궁동의 1,2 월 오존도는 결측자료 이므로 $5 \mathrm{~km}$ (lagdist=4.9958)내에 있는 지역의 오존들을 평균을 이용하여 성수동(1월:0.010ppm, 2 월:0.013ppm)과 궁동(1월:0.005ppm, 2월:0.012ppm)의 오존도로 대체하여 사용하였다.

먼저 구의동의 오존도를 예측하기 위해 구의동을 제외한 26개 모든 측정소의 월별 오존도 자료 를 보통 크리깅 방법과 거리역수 크리깅 방법을 이용하여 두 크리깅 방법을 비교하였다.

\subsection{1 보통 크리깅 방법}

구의동의 오존도를 예측하기 위해 월별 이론적 차의 분산(가우스 모형)에 적합된 모형식의 $C(0)$ 와 $a_{s}$ 는 <표 7 >과 같다. 여기서 $2,10,11,12$ 월의 오존도는 정규성을 만족하지 않으므로 로 그변환 후 분석하였으며 보통 크리깅의 가중값을 이용하여 구한 구의동 오존도의 예측값과 실제 값을 비교해보면 <표 8>과 같고, 이를 그래프화한 것이 <그림 4 >이다.

\section{2 .2 거리역수 크리깅 방법}

다른 크리깅 방법인 거리역수 크리깅 방법을 이용하여 동일한 월별 오존 자료에 대한 가중값을 계산하면 월별에 따른 오존자료는 전혀 영향을 받지 않고 단순한 거리에 의해서만 영향을 받는다 는 것을 알 수 있다. 거리역수 크리깅 가중값을 이용하여 구한 구의동 오존도의 예측값과 실제값 을 구한 결과는 <표 8>에 보통 크리깅 방법을 이용한 예측값과 같이 나타나 있으며 이를 그래프 
430 Jihui Jang, Taekyong Hong, Pyong Namkung

로 나타낸 것이 <그림 4>에 나타나 있다

<표 6>27개 지역의 2000년 월별 오존자료 (ppm)

\begin{tabular}{|c|c|c|c|c|c|c|c|c|c|c|c|c|}
\hline & 궐 & 2월 & 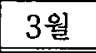 & 월 & 월 & 6월 & 월 & 8월 & 9월 & 월 & 11 월 & \\
\hline & 013 & 015 & 019 & 24 & & 021 & 017 & 008 & 209 & & 008 & \\
\hline 하 & & & & & & & & & & & & \\
\hline 목동 & & & & & & & & & & & & \\
\hline 설 동 & & & & & & & & & & & & \\
\hline 광동 & & & & & & & & & 25 & & & \\
\hline 마포 & & & & 7 & & & & & 8 & & & \\
\hline 문래동 & 014 & & & & 0. & & 66 & 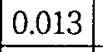 & 9 & & & \\
\hline 당동 & & & & & & & & & & & & \\
\hline 간악산 & 018 & & & 9 & 0. & & 1 & i & 0.028 & & 15 & \\
\hline 기치동 & & & & 0 & & & & 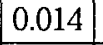 & 0.017 & & & \\
\hline 실동 & & & & & & & & & & & & \\
\hline 시홍동 & & & & 9 & 0.0 & & & 2 & 1 & & & \\
\hline 천호동 & & & & & & & & 4 & & & & \\
\hline 번동 & 003 & & & 3 & 0.020 & & & 7 & 3 & & & \\
\hline 길음동 & & & & 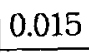 & & & & 1 & 0.0 & & & \\
\hline 한남동 & & & & 3 & & & & 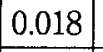 & 1 & & & \\
\hline 구의동 & & & & 4 & & & 0 & 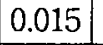 & 0.0 & & & \\
\hline 성수동 & & & & 7 & & & & & & & & \\
\hline 학동 & 016 & & & 0. & & & 9 & 0.018 & 0.020 & & & \\
\hline 가좌동 & 0. & & & 3 & & & & 4 & & & & \\
\hline 구로동 & 0 & & & 0.02 & 0.0 & & 84 & 0.014 & 0.015 & & & \\
\hline 반포동 & & & 1 & 5 & 0.0 & & & 13 & 0.016 & & & \\
\hline 화곡동 & 0 & & & 0.020 & 0.0 & & 3 & 0.014 & 0.016 & & 0.008 & \\
\hline 방이동 & & & & 4 & 6 & & & 013 & 0.013 & & 08 & \\
\hline 정동 & & & & $\pi$ & & & & 0.017 & 0.017 & & 5 & \\
\hline 상계동 & 21 & & & 9 & 0.029 & & & 0.020 & 0.023 & & 19 & \\
\hline & & & & & & & & & & & & \\
\hline
\end{tabular}


<표 7> 이론적 차의 분산에 적합된 $C(0)$ 와 $a_{s}$

\begin{tabular}{c||c|c}
\hline & $C(0)$ & $a_{s}$ \\
\hline \hline 1월 & 0.0000192 & 2.5 \\
\hline 2월* & 0.014 & 2.4 \\
\hline 3월 & 0.0000355 & 3.1 \\
\hline 4월 & 0.0000445 & 3.2 \\
\hline 5월 & 0.00003 & 1.55 \\
\hline 6월 & 0.0000204 & 2.0 \\
\hline 7월 & 0.000016 & 3.5 \\
\hline 8월 & 0.0000193 & 1.0 \\
\hline 9월 & 0.0000275 & 2.0 \\
\hline 10월* & 0.026 & 2.5 \\
\hline 11월* & 0.030 & 3.2 \\
\hline 12월* & 0.025 & 3.3 \\
\hline
\end{tabular}

<표 8> 구의동 오존도의 실제값과 보통 크리깅 예측값, 거리역수 크리깅 예측값

\begin{tabular}{c||c|c|c}
\hline 월별 & 실제값 & $\begin{array}{c}\text { 보통 크리깅 } \\
\text { 예측값 }\end{array}$ & $\begin{array}{c}\text { 거리역수 } \\
\text { 크리깅 예측값 }\end{array}$ \\
\hline \hline 1월 & 0.009 & 0.010 & 0.010 \\
\hline 2월 & 0.010 & 0.012 & 0.014 \\
\hline 3월 & 0.017 & 0.015 & 0.018 \\
\hline 4월 & 0.024 & 0.023 & 0.022 \\
\hline 5월 & 0.024 & 0.023 & 0.023 \\
\hline 6월 & 0.027 & 0.026 & 0.026 \\
\hline 7월 & 0.026 & 0.026 & 0.025 \\
\hline 8월 & 0.015 & 0.015 & 0.015 \\
\hline 9월 & 0.019 & 0.017 & 0.017 \\
\hline 10월 & 0.010 & 0.009 & 0.011 \\
\hline 11월 & 0.008 & 0.005 & 0.008 \\
\hline 12월 & 0.007 & 0.005 & 0.009 \\
\hline \multicolumn{3}{|c}{}
\end{tabular}

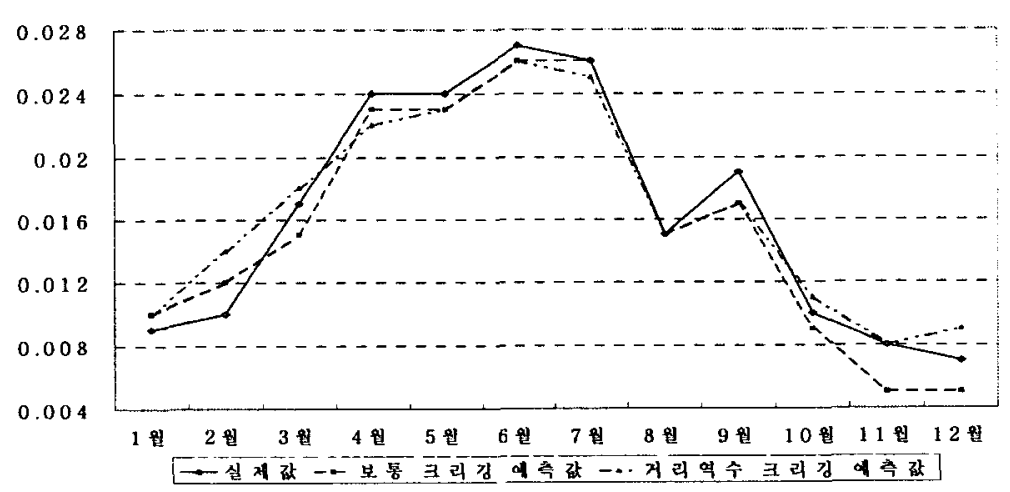

<그림 4> 구의동 오존도 실제값과 보통, 거리역수 크리깅 예측값 그래프

두 크리깅 방법을 이용한 예측값 중 어떤 예측값이 실제 구의동 오존도를 잘 설명하는지를 보 다 면밀히 알아보기 위해 임의로 측정소의 수를 26 개, 24 개, 18 개, 18 개(거리고려)로 줄여 가며 앞 의 방법과 동일한 방법으로 분석하여 예측오차를 비교하였다.

결과는 〈표 9> 에 나타나 있듯이 모든 경우에서 보통 크리깅 예측값이 거리역수 크리깅 예측값 보다 실제값과의 예측오차가 작게 나타나 보통 크리깅 예측값이 보다 정확한 예측값이 된다.

<표 9> 측정소 개수별 크리깅 방법 비교

\begin{tabular}{c|c||c|c|c|c}
\hline \multicolumn{2}{c|}{} & 26 개 측정소 & 24 개 측정소 & 18 개 측정소 & $\begin{array}{c}\text { 18개 측정소 } \\
\text { (거리고려) }\end{array}$ \\
\hline \hline \multirow{2}{*}{ 예측오차 } & 보통 크리깅 & 0.016 & 0.007 & 0.011 & 0.017 \\
\cline { 2 - 6 } & 거리역수 크리깅 & 0.017 & 0.017 & 0.013 & 0.019 \\
\hline
\end{tabular}




\section{5. 결론}

미 측정 또는 측정의 신뢰도가 떨어지는 측정소의 오존을 예측하기 위한 보통 크리깅 방법은 주변 기지점과의 거리 및 오존도를 고려하며, 거리역수 크리깅 방법은 거리만이 고려 대상이 된 다. 따라서 두 크리깅 방법의 차이는 오존도의 상대적 크기 차를 어떻게 반영하는가에 있으며, 각 각 오존도의 크기와 거리, 단순 거리 등이 가중값을 구성하게 되는 것이다.

분석 결과 미 측정소인 구의동 오존 예측도를 $100 \%$ 신뢰한다고 가정하면 두 크리깅 방법 중 보통 크리깅 방법이 다소 좋은 결과로 나타났는데 이것은 두 크리깅 방법 간의 차이는 그다지 크 지 않으며, 오존도의 공간적 변동성은 그 거리의 차이에 비해 미미하다는 것으로 가중값은 오존도 보다는 측정소 간의 거리에 의존한다는 것이다.

또한 측정소 개수를 줄이는 경우도 미미한 차이로 보통 크리깅 예측값이 실제값에 가까운 결과 로 나타났으나 구의동으로부터 거리가 먼 18 개 측정소 자료만을 이용한 결과는 무작위로 선택한 18 개 측정소 자료만을 이용했을 경우보다 예측오차가 큰 것으로 보아 공간 상 거리가 멀어지면 예 측값에 영향을 줄 수 있다는 것을 알 수 있었다.

이러한 결과는 크리깅 방법은 실제 미 측정 오존도 예측에 효율적으로 이용될 수 있을 것이고, 정규성과 lag문제가 발생되지 않는다면 보통 크리깅 방법을 사용하고 반면, 정규성을 만족하나 $\operatorname{lag}$ 문제가 발생한다면 적절한 보통 크리깅 예측값을 얻을 수 없으므로 거리만을 가중값으로 두는 거리역수 크리깅 방법을 이용하는 것이 바람직할 것으로 판단된다.

\section{참고문헌}

[1] 박성현 (1996), 우리나라 환경통계의 현황, 응용통계연구, 제9권 1호, pp. 179-202.

[2] 유성모, 엄익현 (1997), 강우강도자료를 이용한 semi-variogram의 추정과 예측, Proceedings of the Spring Conference, Korean Statistical Society.

[4] 한국수자원공사 (1996), Kriging기법을 이용한 강우 공간분포에 관한 연구.

[5] Cressie, N. (1989). Spatial Prediction and Ordinary Kriging, Mathematical Geology, 21, pp. 493-494.

[6] Cressie, N. (1991), Statistical for Spatial Data, New York, Wiley.

[7] Isobel Clack. and Paker, H. (1980), Geostatistics, Mackay School of Mines.

[8] Jean-Paul Chiles Pierre Delfiner (1999), Geostatistics Modeling Spatial Uncertainty, John Wiley \& Sons, Inc.

[9] Matheron, G.(1963), Principles of Geostatistics, Economic Geology, 58, pp.1246-1266

[10] Sacks, et. al. (1989), DACE(Design and Analysis of Computer Experiments).

[11] Steven K. Thompson (1992), Sampling, John Wiley \& Sons, Inc.

[12] William, V. H. and Isobel Clack. (2000), Practical Geostatistics 2000, Ecosse North. 